\title{
sciendo
}

\section{IMPACT OF DIFFERENT REARING SYSTEMS AND AGE ON BOVANS WHITE LAYER'S PERFORMANCE, EGG QUALITY TRAITS AND SYNTHESIS OF HEAT SHOCK PROTEIN 70 kDa}

\author{
Yasin Baykalir*, Ulku Gulcihan Simsek \\ Department of Animal Science, Firat University, Üniversite Mah, 23119 Elazig, Turkey \\ •Corresponding author: ybaykalir@firat.edu.tr
}

\begin{abstract}
This study was conducted to investigate the performance of laying hens and to determine possible age-related changes on external and internal quality traits of their eggs and synthesis of heat shock protein $70 \mathrm{kDa}$ (HSP70) in the conventional cage and organic rearing systems. For this purpose, 4 different Bovans White hybrid flocks of the same age were monitored in each of these two systems for 52 weeks. While a total of 360 eggs were examined to determine the effects of rearing system and age (30 and 60 weeks) on egg quality traits, 48 liver tissue samples were examined for the analysis of HSP70. Egg production (hen-day) and dirty egg ratio were higher in the organic rearing system $(\mathrm{P}<\mathbf{0 . 0 5})$. The age at $\mathbf{5 0 \%}$ yield, the age at peak of lay, and peak production rate were calculated as $156,218.75$ days and $95.98 \%$ in the conventional system, and $155.75,201.50$ days, and $96.56 \%$ in the organic system, respectively $(\mathrm{P}>\mathbf{0 . 0 5})$. While egg weight, albumen weight, yolk weight, shell weight, shape index, and yolk colour were higher in the organic system, the crude ash ratio of eggshell and shell ratio were higher in the conventional system $(\mathrm{P}<0.05)$. It was also found that the egg weight, albumen weight, yolk weight, shell weight, and the percentage of yolk were higher at 60 weeks of age $(P<0.001)$. The percentage of shell and albumen, shape index, and yolk colour were higher at 30 weeks of age $(\mathrm{P}<\mathbf{0 . 0 0 1})$. The interactions between rearing system and age were statistically significant in terms of shell thickness, shape index, crude ash ratio, and yolk colour $(\mathrm{P}<\mathbf{0 . 0 0 1})$. Stress protein $(\mathrm{HSP70})$ level was affected only by the rearing system and was higher in the organic system $(\mathrm{P}<\mathbf{0 . 0 0 1})$. As a result, the organic system can be considered as advantageous in terms of egg production and quality traits and the eggs of young hens exhibited better properties. The high level of HSP70 in the organic system could indicate that hens were affected by the environmental conditions at higher rates and/or the hens reared in the organic system had a stronger antioxidant defence system.
\end{abstract}

Key words: egg quality, HSP70, laying hens, performance, rearing systems

Biological characteristics of hens and high production capability per unit area allow different rearing systems to be used for table egg production. Conventional battery cages are widely used in the egg industry because of the space savings, reduced labour, and equipment costs. However, the behavioural repertoire of hens is 
limited in these conventional cages, which may be considered as a problem in terms of animal welfare (Thomas and Ravindran, 2005). Despite the European Union's ban, $14 \%$ of hens in Europe are still reared in the conventional battery cages. Additionally, it is emphasised that consumers prefer table eggs obtained from welfare friendly rearing systems. Egg quality traits also have an important effect on customer demands (Krawczyk, 2009). In this context, many consumers believe that organically produced eggs are better quality compared to eggs from the conventional battery cage system (Stanley et al., 2014). Some studies revealed different results for conventional and organic systems in terms of egg production (Minelli et al., 2007; Mugnai et al., 2009; Holt et al., 2011; Englmaierová et al., 2014). Egg production is generally higher in the conventional cage system than in the organic system. Moreover, feed conversion ratio, feed consumption, and the number of dirty and cracked eggs are lower in the conventional cage system (Golden et al., 2012; Denli et al., 2016; Perić et al., 2016).

With increasing age, functions of cells and hormones are reduced and some alterations occur in body composition (Barzilai et al., 2012). Egg quality is also affected by the age of the laying hens. While egg weight and percentage of yolk increase with aging, shape index, shell quality and percentage of albumen decrease (Singh et al., 2009). In addition, Chang-Ho et al. (2014) determined that the yolk colour changed at different periods of the laying cycle.

The effect of stress is well known in poultry farming. The response to stress in organisms is observed in two forms as physiological and cellular. At the cellular level, the antioxidant system and heat shock proteins (HSP) are activated to detect and control different forms of stress (Calabrese et al., 2007; Dattilo et al., 2015). HSPs are a family of molecular chaperones which have a crucial role in the protein folding mechanism. HSPs are classified according to their molecular weight ranging from 10 to $150 \mathrm{kDa}$. Under stress conditions, the heat shock protein $70 \mathrm{kDa}$ (HSP70) is the most effective one (Patir and Upadhyay, 2010). The studies conducted on HSP70 in poultry have been mostly related to heat stress (Gu et al., 2012; Tamzil et al., 2013). HSP70 is accepted to be a potential indicator for adaptation of animals to harsh environmental conditions (Hansen, 2004).

In the light of such information, the aim of this study was to investigate performance parameters and to determine age-related changes in egg quality traits and synthesis of the HSP70 among laying hens reared in conventional cage and organic systems.

\section{Material and methods}

\section{Animal material, rearing systems, and experimental design}

The study was conducted at a commercial egg company once the approval of Firat University Animal Researches Local Ethics Committee (FUHADYEK, permission no: 05.11.2014/206) was obtained. In the study, Bovans White, a commercial white layer hybrid, was used as the strain of laying hen. The company rears one- 
day-old chicks in their own chick growing units for 16 weeks, afterwards the pullets were transferred to the rearing systems. The feed was produced at the feed mill of the company in accordance with National Research Council (NRC, 1994) standards. The hens were fed with the feed and drinking water ad libitum and similar ingredients were used when formulating diets in both systems. Table 1 shows the composition of the diet. The study was carried out in a $2 \times 2$ factorial experimental design. The rearing system (conventional cage and organic systems) and the hen's age (two different flocks aged 30 weeks and 60 weeks) were the main factors. In order to avoid seasonal effects, both systems and age groups were synchronised in January and February for egg quality traits and HSP70 analyses.

Table 1. Composition of the feeds

\begin{tabular}{|c|c|c|}
\hline Feed ingredients (\%) & $\begin{array}{c}\text { Conventional cage and Organic } \\
18-36 \text { weeks } \\
\end{array}$ & $\begin{array}{l}\text { Conventional cage and Organic } \\
52-65 \text { weeks }\end{array}$ \\
\hline Maize* & 27.00 & 27.60 \\
\hline Wheat* & 20.00 & 24.85 \\
\hline Wheat bran* & 9.00 & 5.28 \\
\hline Soybean meal* $\left(48 \% \mathrm{CP}^{1}\right)$ & 16.20 & 17.15 \\
\hline Sunflower meal* $(32 \% \mathrm{CP})$ & 6.64 & 5.90 \\
\hline Maize gluten*(43\% CP) & 4.76 & 3.00 \\
\hline Vegetable oil* & 5.60 & 5.35 \\
\hline DL-methionine & 0.12 & 0.08 \\
\hline L-lysine hydrochloride & 0.01 & - \\
\hline L-threonine & 0.01 & - \\
\hline L-tryptophan & 0.01 & - \\
\hline Dicalcium phosphate & 1.63 & 1.41 \\
\hline Ground limestone & 8.60 & 3.70 \\
\hline Sodium bicarbonate & 0.10 & 5.40 \\
\hline Salt & 0.16 & - \\
\hline Vitamin-mineral mixture ${ }^{* *}$ & 0.16 & 0.28 \\
\hline \multicolumn{3}{|l|}{ Nutrient composition (\%): } \\
\hline dry matter & 90.9 & 90.8 \\
\hline crude protein & 17.8 & 16.7 \\
\hline total phosphorus & 0.38 & 0.34 \\
\hline calcium & 3.76 & 3.90 \\
\hline sodium & 0.15 & 0.15 \\
\hline methionine & 0.73 & 0.65 \\
\hline lysine & 0.84 & 0.84 \\
\hline threonine & 0.67 & 0.65 \\
\hline tryptophan & 0.24 & 0.24 \\
\hline $\operatorname{ME}(\mathrm{Kcal} / \mathrm{kg})$ & 2718 & 2741 \\
\hline
\end{tabular}

${ }^{1} \mathrm{CP}$ : Crude protein. *For the organic system, organic feed raw materials were used.

**Vitamin mix (per 2.5kg): vitamin A 12,000,000 IU; vitamin $\mathrm{D}_{3} 2,000,000 \mathrm{IU}$; vitamin E 35,000 mg; vita$\min \mathrm{K}_{3}$ 4,000 mg; vitamin $\mathrm{B}_{1} 3,000 \mathrm{mg}$; vitamin $\mathrm{B}_{2}$ 7,000 mg; niacin 20,000 mg; calcium D-pantothenate 10,000 $\mathrm{mg}$; vitamin $\mathrm{B}_{6} 5,000 \mathrm{mg}$; vitamin $\mathrm{B}_{12} 15 \mathrm{mg}$; folic acid 1,000 mg; D-biotin $45 \mathrm{mg}$; vitamin C 50,000 mg; choline chloride 125,000 mg; canthaxanthin 2,500 mg; apo carotenoic acid ester $500 \mathrm{mg}$.

Mineral mix (per $1 \mathrm{~kg}$ ): manganese 80,000 mg; iron 60,000 mg; zinc 60,000 mg; copper 5,000 mg; cobalt $200 \mathrm{mg}$; iodine 1,000 mg; selenium $150 \mathrm{mg}$. 


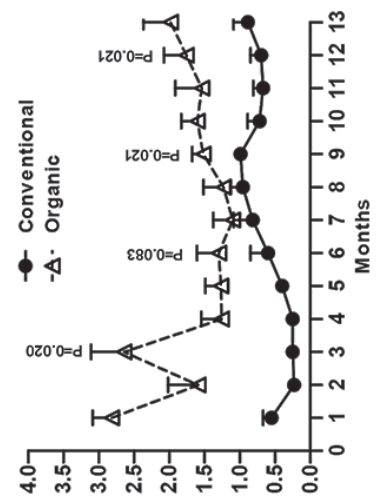

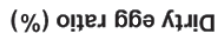

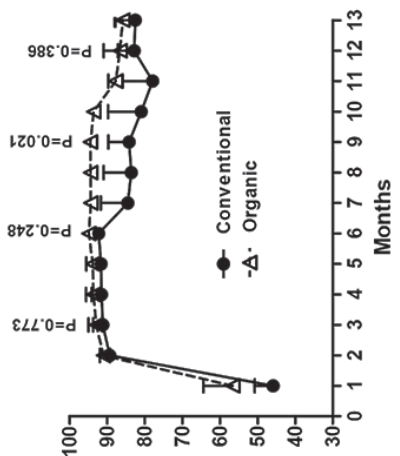

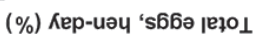
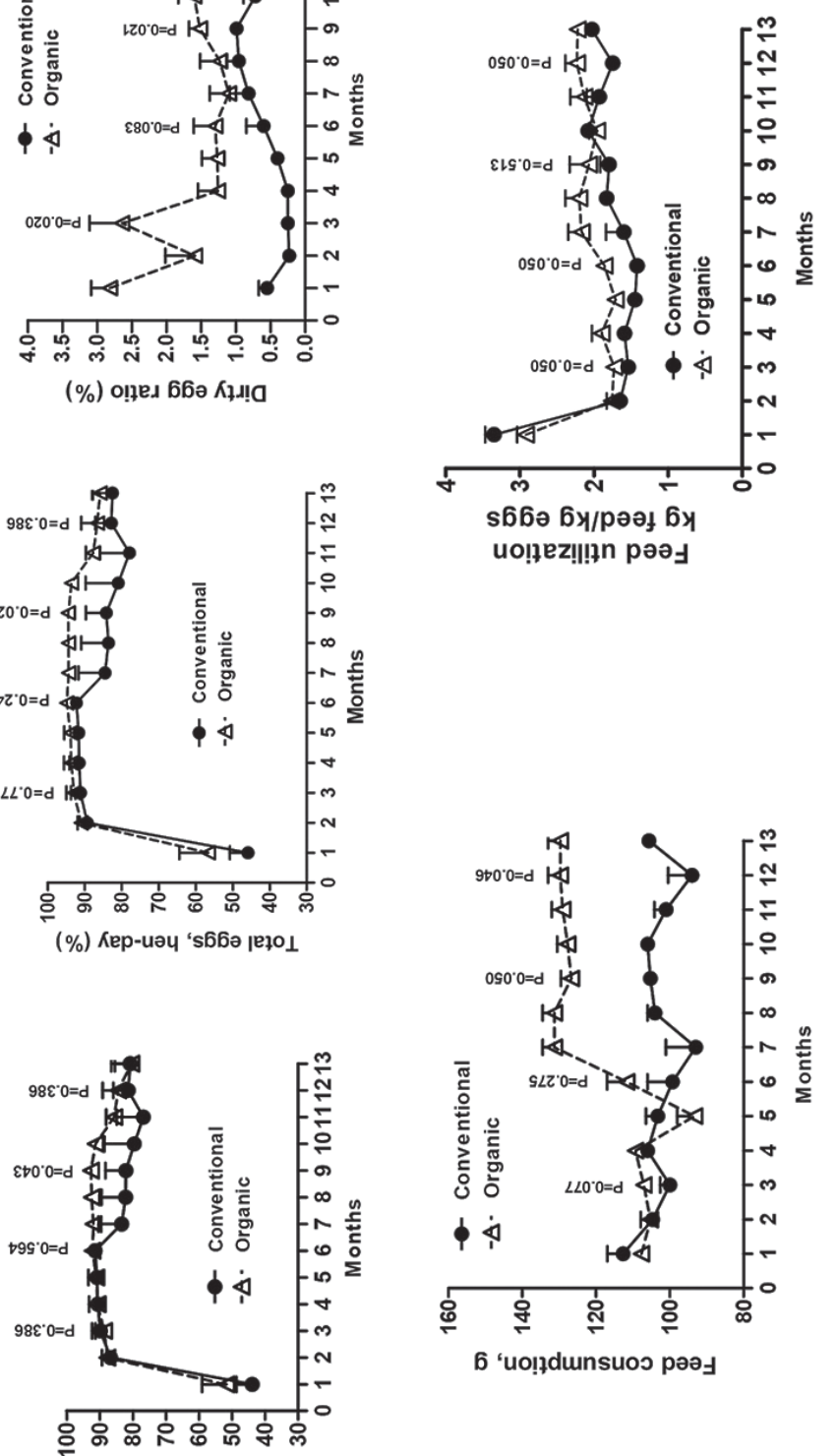

s66ә 6х/рәәу 6x

uo!̣ız!!!!n рәәу

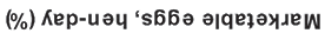

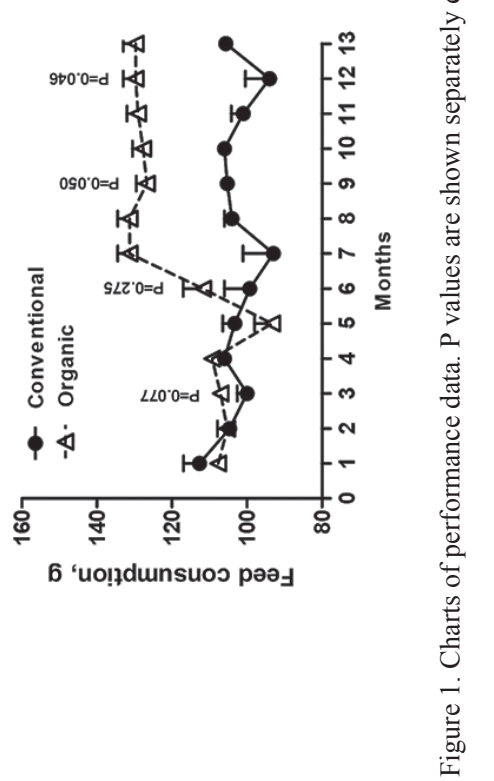


Conventional cages in the company had 4 tiers and sizes of each cage unit were $70 \mathrm{~cm}$ width $\times 55 \mathrm{~cm}$ length $\times 50 \mathrm{~cm}$ height. In this system, the flock size was around 40000 hens. There were 7 hens in each cage unit. Each cage unit had 3 nipple drinkers and a $70-\mathrm{cm}$ long (10 $\mathrm{cm}$ per bird) trough type feeder. Manure was removed out of the house by scraper belts. Artificial lighting was performed during the laying period in the cages. The dark/light period of $8 / 16$ hours was implemented for 25 weeks. Eggs were collected automatically by egg belts in this system.

Organic production was also carried out in an outdoor area. Each organic house was established on an enclosed litter floor pen of $560 \mathrm{~m}^{2}\left(5-6 \mathrm{bird} / \mathrm{m}^{2}\right)$ and an outdoor area of $12000 \mathrm{~m}^{2}\left(4 \mathrm{~m}^{2}\right.$ per hen) for 3000 hens. The outdoor area was covered with natural vegetation. The pop-holes were placed along one side of the house to provide free access for hens to the outdoor area when the weather conditions were appropriate. The floor pen had 120 circular hanging feeders and 200 nipple drinkers. The lighting regime was similar to the conventional cage system, a dark/light period of $8 / 16$ hours was performed indoor the house.

\section{Performance data}

For the performance data of the study, 4 different Bovans White hybrid flocks of the same age were monitored from each of the two systems for 52 weeks (between 20 weeks of age and 72 weeks of age). The data were obtained for each flock by visiting the company at 2-month intervals. Some parameters are given as monthly charts (Figure 1). A number of saleable, dirty, cracked-broken, double-yolked eggs, as well as mortality rate and feed consumption values were recorded between 20 and 72 weeks of age. Based on the daily collected egg number, age at $50 \%$ yield, peak hen-day egg production rate, and age at peak of lay of the hens were determined. The hen-day egg production was calculated by dividing the number of daily collected saleable eggs by the number of hens on the same day. The hen-day total egg production was calculated by dividing the number of daily collected total eggs (saleable, dirty, cracked-broken, and double-yolked eggs) into the number of hens on the same day, and multiplying the result by one hundred. The other parameters such as dirty, cracked-broken, and double-yolked eggs and the mortality rate were calculated on a daily basis as given in the hen-day formula. The total mortality rate was also calculated by dividing total number of dead hens into number of hens at the beginning of the breeding period. Daily feed consumption (g/bird/day) and feed utilisation ( $g$ feed per egg, $\mathrm{kg}$ eggs/kg feed, $\mathrm{kg}$ feed/kg eggs) were calculated.

\section{Egg quality traits}

A total of 360 eggs were examined for investigating egg quality traits. Ninety eggs were randomly collected from both systems and age groups twice a week $(2$ systems $\times 2$ age groups $\times 90$ eggs). It was considered that the eggs were collected from different regions of the houses. The eggs from each group were brought to the laboratory and kept in the refrigerator for one day. Firstly, the eggs were weighed (A\&D, FX-300i, Japan) and the shape index was then determined by using a digital calliper (Tresna, 0-300 mm, USA). The shape index value was obtained by dividing egg width into the egg length and multiplying the result by one hundred. Then, the 
eggs were broken and the egg's albumen was separated from the yolk. Both albumen and yolk were weighed separately in sterile cups. The yolk colour was determined by a Roche yolk colour fan. The eggshells were thoroughly rinsed with clean water, allowed to dry for 24 hours under laboratory conditions, and then weighed. Eggshell thickness was then determined by using a micrometre (Mitutoyo, Model No 2050-08, Japan). For the crude ash analysis of the eggshells, each eggshell was compressed in a porcelain pot after the eggshell thickness was determined. Before using the porcelain pots, the eggshells were dried in the oven at $100^{\circ} \mathrm{C}$ for $30 \mathrm{~min}$. The tares of the pots were recorded (a). The eggshells and pots were weighed together and recorded (b). The samples were burned in the crude ash oven at $550^{\circ} \mathrm{C}$ for $3-4$ hours. Upon completion of this period, the samples were removed from the oven and cooled in a desiccator to the room temperature. The samples were weighed again (c).

The crude ash values of the samples were calculated by using the following formula:

$\%$ crude ash $(C A)=[(c-a) /(b-a)] \times 100(A O A C, 1995)$.

Percentages of albumen, yolk, and shell were calculated by the following formulas (Simsek et al., 2015):

percentage of albumen: (albumen weight/egg weight) $\times 100$;

percentage of yolk: (yolk weight/egg weight) $\times 100$;

percentage of shell: (shell weight/egg weight) $\times 100$.

\section{The HSP70 analysis of liver tissues by the method of Western blot}

For HSP70 analysis, a total of 48 hens were chosen from different regions of the hen houses $(2$ systems $\times 2$ age groups $\times 12$ hens $)$. The livers were resected following euthanasia of the hens decapitated and stored at $-70^{\circ} \mathrm{C}$ until the analysis. Liver samples $(0.5 \mathrm{~g})$ were homogenised in glass laboratory tubes, using $4.5 \mathrm{ml}$ tissue homogenisation buffer $(20 \mathrm{mM}$ Tris- $\mathrm{HCl}, \mathrm{pH} 7 \cdot 4)$. The samples were homogenised 3 times (30 seconds) using a bladed homogeniser (Witeg, WiseTis, Germany) at $17000 \mathrm{rpm}$ and with ice-bath intervals of 30 seconds. Each sample was centrifuged at $31000 \mathrm{~g}$ for $10 \mathrm{~min}$ at $4^{\circ} \mathrm{C}$ (Hettich, USA). The supernatant was transferred to $1.5 \mathrm{ml}$ eppendorf tubes. Two aliquots of $1.5 \mathrm{ml}$ were separated for protein quantification and electrophoresis.

Protein quantification was conducted using a fluorometer (Invitrogen, Qubit 2, USA) with the protein assay kits supplied by the manufacturer in accordance with the instructions of the manufacturer. The SDS-PAGE analyses of protein samples were carried out according to Laemmli (1970). Loading sample buffer (Bio-Rad, $4 \mathrm{X}$ Sample buffer, USA) was added to the electrophoresis samples and they were boiled at $95^{\circ} \mathrm{C}$ for $5 \mathrm{~min}$. Total protein was loaded as $30 \mu \mathrm{g} / 30 \mu \mathrm{l}$ to $12 \%$ separating polyacrylamide gel. The prestained protein weight marker was added to first and last wells of the gel. Electrophoresis was carried out at a constant voltage of $120 \mathrm{~V}$ for 90 min (Bio-Rad, MiniProtean Tetra, USA). In this study, Western blot analyses were conducted by applying a few minor modifications to the method described by Towbin et al. (1979). Following electrophoresis, protein samples were electrophoretically transferred to $0.45-\mu \mathrm{m}$ thick nitrocellulose membranes under semi-dry con- 
ditions (Bio-Rad, Turbo Blotter, USA). Non-specific binding sites on the membranes were blocked with $5 \%$ bovine serum albumin for overnight. The membranes were incubated with mouse monoclonal anti-HSP70 antibody (Sigma, Saint Louis, MO) (1:1000 dilution) at room temperature for 2 hours. The membranes were washed 4 times ( $5 \mathrm{~min}$ ) with TBS-Tween20, then incubated with chicken anti-mouse IgG secondary antibody conjugated to horseradish peroxidase (Santa Cruz Biotechnology, Dallas Texas, USA) (1:5000 dilution). The bands on the membrane were detected with 3,3'-diaminobenzidine (Figure 2). In order to verify equal loading of samples, the membrane was incubated with mouse monoclonal $\beta$-actin antibody (Santa Cruz Biotechnology, Dallas Texas, USA) (1:1000 dilution) and then incubated with an HRP-conjugated chicken anti-mouse IgG antibody (Santa Cruz Biotechnology, Dallas Texas, USA) (1:5000 dilution). The bands were again visualised with 3,3'-diaminobenzidine (Figure 2). Each HSP70 and $\beta$-actin membrane containing the bands was scanned and transferred to the computer. The ImageJ (NIH image) image processing software program was used to evaluate the bands on the membrane. The images were transformed into 8-bit black and white forms and calibrated to grey colour scale by using the software program. The relative densitometry of HSP70 bands was normalised to bands of $\beta$-actin (Gassmann et al., 2009).

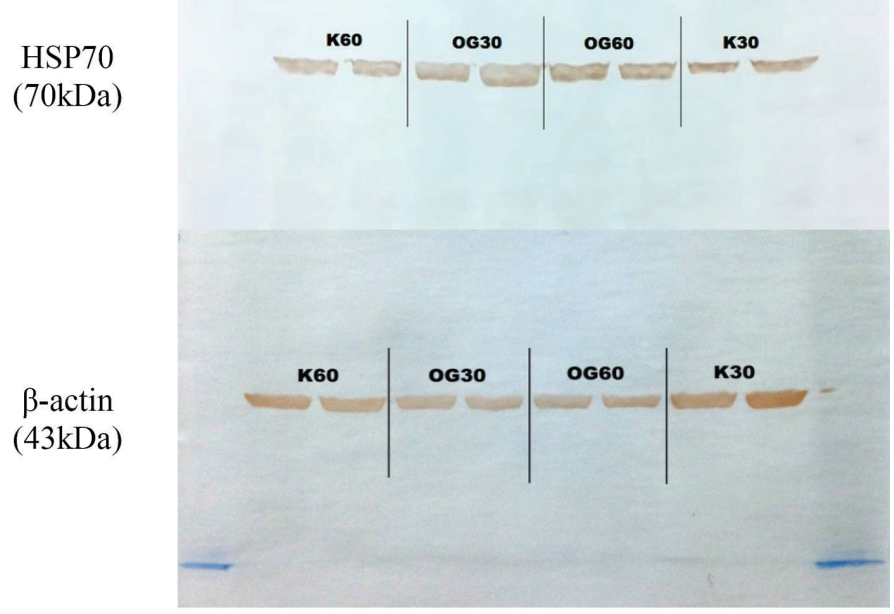

Figure 2. The HSP70 and B-actin bands of the liver tissues on the membranes after the method of Western blotting (K60: Conventional cage - 60 weeks of age, OG30: Organic - 30 weeks of age, OG60: Organic - 60 weeks of age, K30: Conventional cage - 30 weeks of age)

\section{Statistical analysis}

Statistical analysis of the study was performed by IBM ${ }^{\circledR}$ SPSS22 (IBM Corporation, New York, USA) package program. The Mann Whitney U test was used to evaluate the performance data of 4 flocks belonging to the conventional cage and organic systems. The General Linear Model (GLM) procedure was applied to egg 
quality traits and HSP70. The data were represented as the mean and standard error of the mean (SEM). The value of $\mathrm{P} \leq 0.05$ was accepted as statistically significant (Collins et al., 2009).

\section{Results}

Table 2 shows the performance of the flocks. There were statistically significant differences between conventional cage and organic groups in terms of total hen-day egg production and dirty egg ratio $(\mathrm{P}<0.05)$. The systems had similar total crackedbroken and double-yolked egg ratios $(\mathrm{P}>0.05)$. There was no difference between conventional and organic systems for daily feed consumption (103.00 and $117.33 \mathrm{~g}$ ), consumed feed per egg (104 and $118.67 \mathrm{~g}$ ), consumed feed per kilogram of eggs $(1.71$ and $1.84 \mathrm{~kg})$, consumed feed per kilogram of eggs produced ( 0.60 and $0.55 \mathrm{~kg})(\mathrm{P}>0.05)$. In Figure 1, the significant difference was observed in the 9 th month of the laying period in terms of both marketable $(\mathrm{P}=0.043)$ and total $(\mathrm{P}=0.021)$ hen-day values. Dirty egg ratio had significant differences in the $3 \mathrm{rd}(\mathrm{P}=0.020)$, 9th, and 12th $(\mathrm{P}=0.021)$ months. Additionally, there were significant differences in the 9th $(\mathrm{P}=0.050)$ and 12 th $(\mathrm{P}=0.046)$ months in terms of feed consumption and 3rd, 6th and 12 th months $(\mathrm{P}=0.050)$ in feed utilisation $(\mathrm{kg}$ feed $/ \mathrm{kg}$ eggs $)$.

Table 2. Performance parameters of the 20- to 72-week-old flocks

\begin{tabular}{lccc}
\hline \multicolumn{1}{c}{ Rearing system } & Conventional cage & Organic & P-values \\
\hline Age at 50\% yield (days) & $156.00 \pm 2.34$ & $155.75 \pm 4.47$ & 0.962 \\
Age at peak of lay (days) & $218.75 \pm 16.00$ & $201.50 \pm 8.92$ & 0.383 \\
Peak egg production, hen-day (\%) & $95.98 \pm 0.71$ & $96.56 \pm 0.55$ & 0.548 \\
Parameters examined between 20 and 72 weeks & & & 0.890 \\
marketable eggs, hen-day (\%) & $81.53 \pm 1.55$ & $86.16 \pm 1.50$ & 0.014 \\
total eggs, hen-day (\%) & $82.94 \pm 1.50$ & $89.18 \pm 1.03$ & 0.495 \\
marketable eggs, hen-housed (\%) & $79.38 \pm 1.73$ & $81.84 \pm 2.91$ & 0.226 \\
total eggs, hen-housed (\%) & $80.73 \pm 1.67$ & $84.65 \pm 2.37$ & 0.042 \\
dirty egg ratio (\%) & $0.61 \pm 0.02$ & $1.66 \pm 0.30$ & 0.483 \\
cracked-broken egg ratio (\%) & $0.57 \pm 0.12$ & $0.70 \pm 0.12$ & 0.257 \\
double-yolked egg ratio (\%) & $0.67 \pm 0.03$ & $0.97 \pm 0.21$ & 0.375 \\
daily mortality rate (\%) & $0.020 \pm 0.003$ & $0.031 \pm 0.010$ & 0.564 \\
total mortality rate (\%) & $7.50 \pm 1.15$ & $10.78 \pm 3.35$ & 0.076 \\
daily feed consumption (g/bird/day) & $103.00 \pm 1.00$ & $117.33 \pm 5.93$ & 0.275 \\
feed utilisation (g feed/per egg) & $104.00 \pm 8.72$ & $118.67 \pm 6.33$ & 0.502 \\
feed utilisation (kg feed/kg eggs) & $1.71 \pm 0.16$ & $1.84 \pm 0.10$ & 0.432 \\
feed utilisation (kg eggs/kg feed) & $0.60 \pm 0.05$ & $0.55 \pm 0.03$ & \\
\hline
\end{tabular}

$\mathrm{P} \leq 0.05$ : the difference between the groups is significant. 


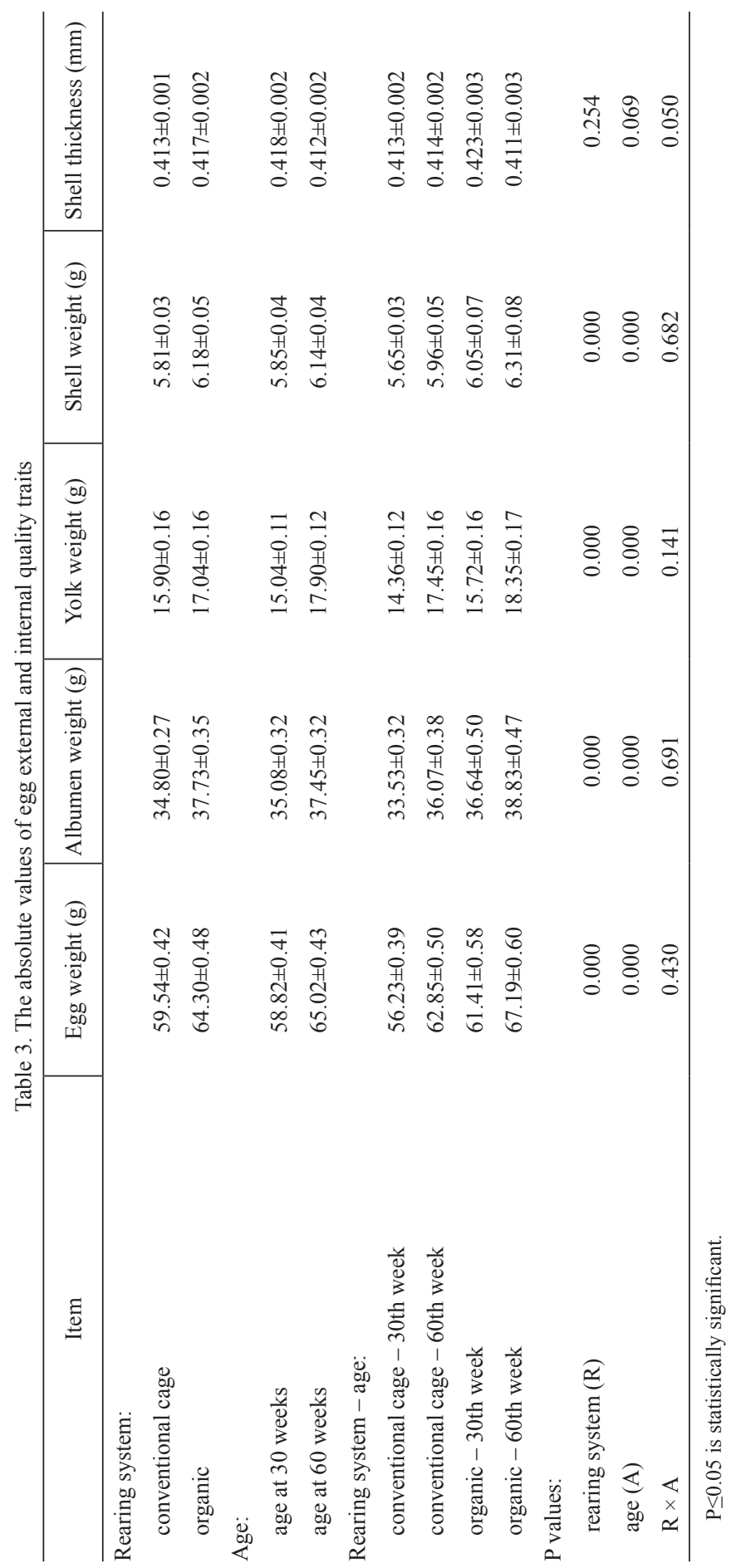




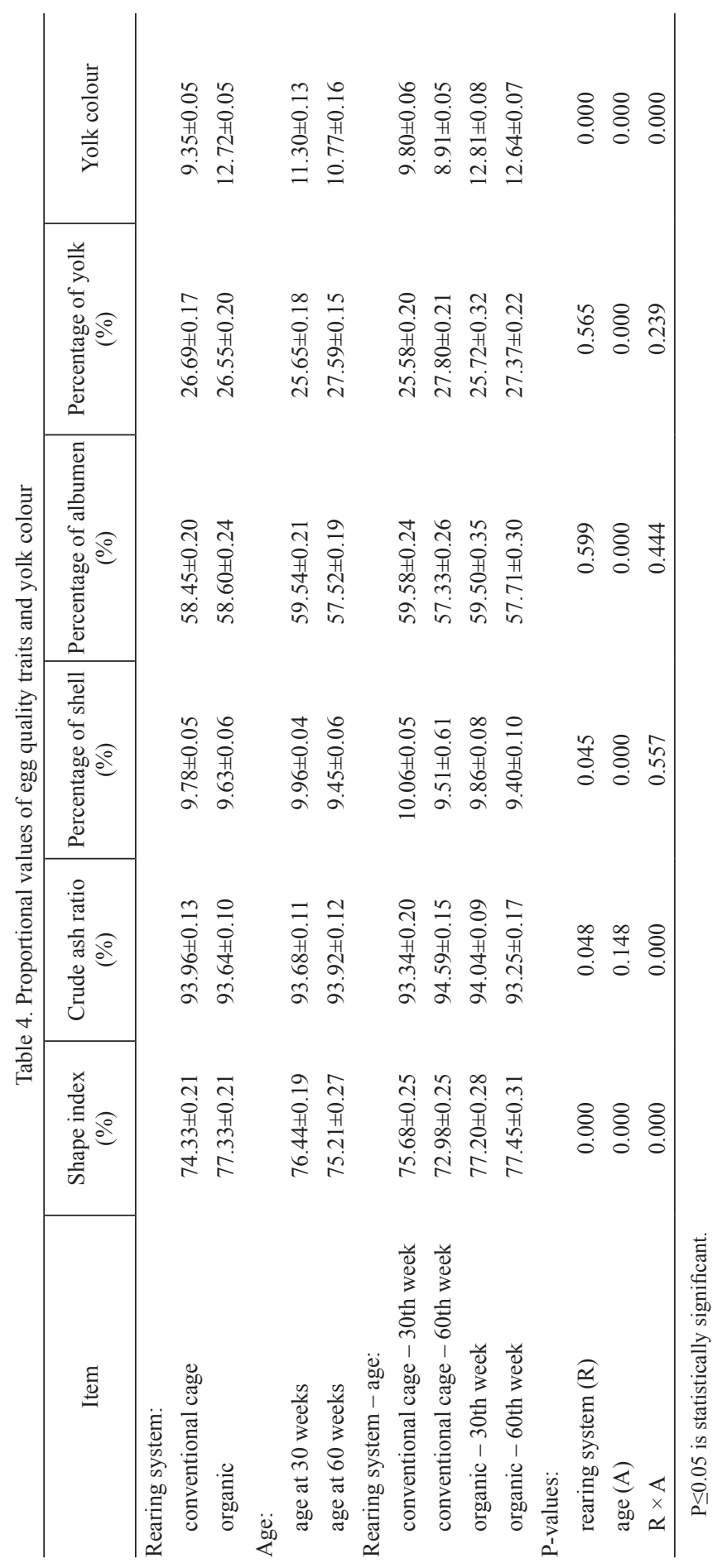


Table 3 shows the absolute values of the examined eggs. Table 4 shows the proportional values and yolk colour. The weights of egg, albumen, yolk, and shell were higher in the organic system and at 60 weeks of age (Table 3). Only age had a significant effect on percentage of albumen and yolk (Table 4). Shape index and yolk colour were higher in the organic hens and at 30 weeks of age $(\mathrm{P}<0.001)$ and there were significant interactions between rearing system and age in terms of these parameters $(\mathrm{P}<0.001)$. Crude ash and shell ratios were higher in the conventional system $(\mathrm{P}<0.05)$ and shell ratio was higher in the younger hens $(\mathrm{P}<0.001)$. The interaction between the rearing system and age significantly affected the crude ash value (Table 4).

Table 5 shows the values related to the effects of rearing system and age on hepatic HSP70 level. The hepatic HSP70 level was exclusively affected by the rearing system $(\mathrm{P}<0.001)$. HSP70 levels were lower in the conventional cage $(0.83)$ than in the organic system (1.14).

Table 5. Effects of rearing system and age on hepatic HSP70 levels among laying hens

\begin{tabular}{lc}
\multicolumn{1}{c|}{ Item } & HSP70 \\
\hline Rearing system: & \\
conventional cage & $0.83 \pm 0.03$ \\
organic & $1.14 \pm 0.04$ \\
Age: & \\
age at 30 weeks & $0.94 \pm 0.05$ \\
age at 60 weeks & $1.03 \pm 0.03$ \\
Rearing system - age: & \\
conventional cage -30 th week & $0.75 \pm 0.05$ \\
conventional cage -60 th week & $0.91 \pm 0.03$ \\
organic -30 th week & $1.15 \pm 0.06$ \\
organic -60 th week & $1.14 \pm 0.06$ \\
P-values: & \\
rearing system (R) & 0.000 \\
age (A) & 0.121 \\
$\mathrm{R} \times$ A & 0.123 \\
\hline
\end{tabular}

$\mathrm{P} \leq 0.05$ is statistically significant.

${ }^{1}$ Relative density values of protein bands obtained in the ImageJ program.

\section{Discussion}

As is seen in Table 2, the age at 50\% yield and age at peak of lay were not significantly different between the conventional and organic systems which is similar to the results of other studies (Pourouchottamane et al., 2012; Yilmaz-Dikmen et al., 2016). These results have suggested that laying hens from the same genotype might not be affected by environmental conditions of rearing systems apart from lighting and feeding regimes (Farooq et al., 2012). Egg production has been reported 
as 66.44-92.86\% in Bovans White (Riberio et al., 2014; Ismail et al., 2015). It is also reported that egg production can exceed $90 \%$ in both conventional and organic systems (Ahammed et al., 2014; Rouf et al., 2015). However, the small number of hens (max. 3000 hens) reared in the organic system might contribute to superior flock management. In one study, it was emphasised that the rearing system did not affect egg production but flock size was significant (Englmaierová et al., 2014). The higher egg production in the organic system in the present study was likely associated with welfare conditions, small flock size management, and regulations of the organic system. In the present study, dirty egg ratio was also found higher in the organic system than in conventional cages. As a result of free ranging, some eggs could be laid outside the nest boxes in the organic system and hens could carry dirty material on their feet to their nest boxes. In addition, the eggs in the nest boxes might be contaminated more depending on the interval between egg collections compared to conventional system. Nest box and perch management, as well as litter type might increase dirty egg ratio. Rainy seasons can increase the dirty egg ratio in free-range systems (Ferrante et al., 2009).

Egg weight and shape index are important quality traits that affect consumer preferences (Rath et al., 2015). Different results on effects of various rearing systems on egg weight have been reported, however, studies are rarely conducted with same strains (Holt et al., 2011). In this study, egg weight and shape index were lower in the conventional cage than the organic system. Egg weight was higher and shape index was lower at the age of 60 weeks compared to the age of 30 weeks. The interaction between rearing system and age was significant for shape index. Ketta and Tumova (2018) determined significant correlations between egg weight and shell weight. In this study, higher shell weight in the organic system might be associated with higher egg weight in this system. Results for shape index were compatible with Lewko and Gornowicz (2011) who reported that caged hens produced eggs with lower shape index than those kept on litter or on free-range.

Shell thicknesses, shell weight, percentage of the shell, shell surface area, and breaking strength are the most examined indicators of shell quality. In this study, shell weight and shell ratio were affected by rearing system and hen's age and there was a significant interaction between rearing system and age for shell thickness. Crude ash value of eggshell, an indicator of mineral content, was higher in the conventional cage than in the organic system in the present study. The higher shell thickness and shell weight in the organic system could be explained by the ingestion of small stones on the outdoor area and exposure to sunlight when the hens were on free-ranging (Kucukyilmaz et al., 2012). The increase in shell thickness associated with aging and higher crude ash value of eggshell in the conventional cage could be due to the effect of amino acid and the vitamin-mineral mixture added only to the feed of the caged hens by the company in around 60th week (Tactacan et al., 2009).

Albumen and yolk weights and their ratios provide information about internal egg quality. In previous studies, albumen and yolk weight were found to be higher in conventional cage systems than organic systems (Minelli et al., 2007), or vice versa (Yilmaz-Dikmen et al., 2017). These values were also similar between the systems (Mugnai et al., 2009). The weights of albumen and yolk generally increase with ag- 
ing (Singh et al., 2009; Ferrante et al., 2009). There was no difference in the percentage of albumen and yolk between the rearing systems (Van Den Brand et al., 2004; Englmaierová et al., 2014). With increasing hen age, the percentage of albumen decreased but the percentage of yolk increased (Zita et al., 2012; Anyaegbu et al., 2016). In this study, albumen and yolk weights were affected by both rearing system and age; whereas, their percentages were affected only by age. Weights of albumen and yolk along with the percentage of albumen were higher in the organic system, but the percentage of yolk was higher in the conventional system. These results were similar to those obtained from the study by Pištěková et al. (2006). Mugnai et al. (2009) reported that both weights and percentages of albumen and yolk were not different between the conventional and organic systems. Kucukyilmaz et al. (2012) reported that percentages of albumen and yolk were higher in the conventional cage system, this result was different from this study in terms of albumen. These results may be associated with the fact that the egg albumen was heavier than the egg yolk and egg size increased with aging (Al-Haweizy and Al-Sardary, 2008). On the other hand, in another study, it was determined that the weight of the albumen decreased with age (Ferrante et al., 2009).

Yolk colour is one of the important quality traits of eggs that affect consumer preference. Consumers usually prefer darker yolk. Nutrition, genetic composition and rearing system all have an effect on yolk colour (Dvořák et al., 2012). Moreover, reduction in liver function, parasites (worms), and nicarbazin are factors that reduce egg yolk pigmentation (Zaghini et al., 2005). In previous studies, variation in yolk colour was determined in rearing systems such as cage, free-range and on litter (Perić et al., 2016). There was no clear finding about yolk colour change with age. Nevertheless, it was determined that yolk colour changed at different periods of the laying cycle (Zita et al., 2012; Chang-Ho et al., 2014). In the present study, yolk colour was affected by the rearing system and age and also there was a significant interaction between rearing system and age. This was associated with consumption of vegetation in the outdoor area (Mugnai et al., 2009; Yenice et al., 2016). Decrease in yolk colour with aging in this study may be explained by digestive (reduced absorption of xanthophylls) and liver function and lipid synthesis reducing with increasing age (Zaghini et al., 2005).

The studies on HSP70 in poultry, in general, are more related to heat stress (Gu et al., 2012; Tamzil et al., 2013). In addition, there is no clear evidence on how changes in HSP70 are related to rearing systems in poultry breeding. In the present study, the relative density value of HSP70 was affected by the rearing system and this value was higher in the organic system than in the conventional system. This might be due to the isolation of the houses in the organic system, the adverse effect of cold weather in winter months, and the exposure of hens to different environmental conditions (Givisiez et al., 2001). HSP70 is known to affect the elimination of toxic effects caused by heat stress. In a previous study on revealing the correlation between HSP70 and oxidative stress, it was emphasised that the overexpression of HSP70 improved antioxidant defence system in broilers ( $\mathrm{Gu}$ et al., 2012). In a previous study, glutathione peroxidase was higher in organic hens than conventional hens and also malondialdehyde was lower (Simsek et al., 2018). In this respect, it was thought 
that the increase of HSP70 synthesis in the organic system may reflect a strong antioxidant system in the hens.

In conclusion, it was observed in this study that the organic system was advantageous in terms of high egg production, egg size, darker yolk colour and better shell quality. It can be asserted that the quality of eggs obtained from young hens is better. High levels of HSP70 in hens reared in organic systems might signify that hens are more affected by environmental conditions or the hens might have a better antioxidant system. More attention should be paid to the environmental conditions of the houses in order to obtain better yields from the organic flocks.

\section{Acknowledgements}

The authors acknowledge all flock owners and employees of the company for providing necessary aid for this study. The authors also appreciate the financial support from Firat University Department of Scientific Research Projects (FUBAP, Grant VF.14.22), Elazig, Turkey.

\section{Clarification}

This article is a part of the corresponding author's Ph.D. thesis entitled "Effects of different rearing systems and age on laying hens' performance, egg characteristics and synthesis of heat shock protein 70".

\section{References}

A ham med M., Cha e B.J., Lohakare J., Ke ohavong B., Le e M.H., Le e S.J., Kim D.M., L e e J.Y., O h h S.J. (2014). Comparison of aviary, barn and conventional cage raising of chickens on laying performance and egg quality. Asian-Australas. J. Anim. Sci., 27: 1196-1203.

A 1 - H a w e i z y A.A., A l - S a r d a r y S.Y. (2008). Effect of dehydrated alfalfa and age on egg weight, albumen percentage, albumen index and haugh units in Hy-line W-98 layers. Acta Fytotechnica et Zootechnica, 1: 25-28.

Any a e gbu B.C., Onunkw o D.N., Ir e bu is i D. (2016). Evaluation of hen age, body weight and egg weight on percent egg component and the internal composition of Harco hen eggs. Sci-Afric. J. Sci. Issues, 4: 943-945.

Association of Official Analytical Chemists (AOAC). (1995). Official methods of analysis. 923.03: 16th ed. Arlington.

B arzila i N., Huffm an D.M., Muzu m dar R.H., B artke A. (2012). The critical role of metabolic pathways in aging. Diabetes, 61: 1315-1322.

Calabrese V., Mancuso C., Sapienza M., Puleo E., Calafato S., Cornelius C., Finocchiaro M., Mangiameli A., Di Mauro M., Giuffrida Stella A.M., Caste 11 in o P. (2007). Oxidative stress and cellular stress response in diabetic nephropathy. Cell Stress Chaperon., 12: 299-306.

Chang-Ho K., Jong-Ho S., J a e-Che on g L., K y un g- Wo o L. (2014). Age-related changes in egg quality of Hy-Line Brown hens. Int. J. Poult. Sci., 13: 510-514.

Collins L.M., D ziak J.J., Li R. (2009). Design of experiments with multiple independent variables: a resource management perspective on complete and reduced factorial designs. Psychol. Methods, 14: 202-224.

Dattilo S., Mancuso C., Koverech G., Mauro P.D., Ontario M.L., Petralia C.C., Petralia A., Luigi Maiolino L., Serra A., Calabrese E.J., Calabrese V. (2015). Heat shock proteins and hormesis in the diagnosis and treatment of neurodegenerative diseases. Immun. Ageing, 12: 20. 
D e n 1 i M., B u k u n B., T u t k un M. (2016). Comparative performance and egg quality of laying hens in enriched cages and free-range systems. Sci. Pap. Ser. D Anim. Sci., LIX: 29-32.

D v ořák P., S u chý P., S trak ová E., Ko privá V. (2012). Possibilities of enhancing the colour of egg yolk. J. Sci. Food Agric., 92: 853-856.

Englmai erová M., Tůmová E., Charvátová V., Skřivan M. (2014). Effects of laying hens housing system on laying performance, egg quality characteristics, and egg microbial contamination. Czech J. Anim. Sci., 59: 345-352.

F a r o o q M., Mi an M.A., D u rran i F.R., S y ed M. (2012). Egg production performance of commercial laying hens in Chakwal district, Pakistan. Pakistan: Livestock Research for Rural Development; http://www.lrrd.org/lrrd14/2/faro142.htm.

F errante V., L olli S., Vezzoli G., Cavalch in i L.G. (2009). Effects of two different rearing systems (organic and barn) on production performance, animal welfare traits and egg quality characteristics in laying hens. Ital. J. Anim. Sci., 8: 165-174.

Gassmann M., Greminacher B., Rohde B., Vogel J. (2009). Quantifying western blots: pitfalls of densitometry. Electrophoresis, 30: 1845-1855.

Givis i e P.E.N., d a S ilva M.M., Mazzi C.M., F erro M.I.T., F e rro J.A., Gonzales E., M a c a r i M. (2001). Heat or cold chronic stress affects organ weights and Hsp70 levels in chicken embryos. Can. J. Anim. Sci., 82: 83-87.

Golden J.B., A rbona D.V., A nders on K.E. (2012). A comparative examination of rearing parameters and layer production performance for Brown egg-type pullets grown for either free-range or cage production. J. Appl. Poult. Res., 21: 95-102.

G u X.H., H a o Y., Wang X.L. (2012). Overexpression of heat shock protein 70 and its relationship to intestine under acute heat stress in broilers: 2. Intestinal oxidative stress. Poultry Sci., 91: 790-799.

H a n s e n P.J. (2004). Physiological and cellular adaptations of zebu cattle to thermal stress. Anim. Reprod. Sci., 82-83: 349-360.

Holt P.S., Davies R.H., D ewulf J., Gast R.K., Huw e J.K., Jones D.R., Waltman D., Willi a n K.R. (2011). The impact of different housing systems on egg safety and quality. Poultry Sci., 90: 251-262.

I s ma i 1 F.S.A., H a y a m M.A., A b o E 1 - M a ty, R a b i e M.H., A s w a d A.Q. (2015). Productive performance of bovans white laying hens fed high nutrient density diets under Egyptian summer conditions. Asian J. Anim. Vet. Adv., 10: 865-874.

K e t t a M., T u m o v a L. (2018). Relationship between eggshell thickness and other eggshell measurements in eggs from litter and cages. Ital. J. Anim. Sci., 17: 234-239.

K r a w c z y k J. (2009). Effect of layer age and egg production level on changes in quality traits of eggs from hens of conservation breeds and commercial hybrids. Ann. Anim. Sci., 9: 185-193.

Kucukyilmaz K., B ozkurt M., Herken E.N., C inar M., Catli A.U., B intas E., Cove n F. (2012). Effects of rearing systems on performance, egg characteristics and immune response in two layer hen genotype. Asian-Austral. J. Anim. Sci., 25: 559-568.

L a e m m li U.K. (1970). Cleavage of structural proteins during the assembly of the head of bacteriophage T4. Nature, 227: 680-685.

Lew k o L., Gornowicz E. (2011). Effect of housing system on egg quality in laying hens. Ann. Anim. Sci., 11: 607-616.

Minelli G., Sirri F., Fole gatt i E., Meluzzi A., Franchini A. (2007). Egg quality traits of laying hens reared in organic and conventional systems. Ital. J. Anim. Sci., 6: 728-730.

Mugnai C., Dal B o s c o A., C a stellin i C. (2009). Effect of rearing system and season on the performance and egg characteristics of Ancona laying hens. Ital. J. Anim. Sci., 8: 175-188.

National Research Council (NRC). (1994). Nutrient Requirements of Poultry. 9th Rev ed. Washington, DC: National Academy of Sci., p. 19.

P a t i r H., Up a dhy a y R.C. (2010). Purification, characterization and expression kinetics of heat shock protein 70 from Bubalus bubalis. Res. Vet. Sci., 88: 258-262.

Perić L., Dukić Stojčić M., Bjedov S. (2016). Effect of production systems on quality and chemical composition of table eggs. Serbian J. Agric. Sci., 65: 27-31.

P ištěková V., Hovorka M., Več e r e k V., S tra k ová E., S u chý P. (2006). The quality comparison of eggs laid by laying hens kept in battery cages and in a deep litter system. Czech J. Anim. Sci., 51: 318-325. 
Pourouchottamane R., Ramesh Saravana Kumar V., Venkatsubramanian V., $\mathrm{K}$ a ta kt a lware M.A., M is hra A., Muzamil S., P a n k j PK. (2012). Influence of rearing system on the production performance of commercial layers. Appl. Biol. Res., 14: 000-000.

R a th P.K., M is h r a P.K., M a 11 i c k B.K., B e hur a N.C. (2015). Evaluation of different egg quality traits and interpretation of their mode of inheritance in White Leghorns. Vet. World, 8: 449-452.

Ribeiro P.A.P., Matos Jr J.B., Lara L.J.C., Araujo L.F., Albuque rque R., B a i o N.C. (2014). Effect of dietary energy concentration on performance parameters and egg quality of white leghorn laying hens. Braz. J. Poultry Sci., 16: 381-388.

R ou f M.G., A ha m m ed M., A h a m m a d M.U., R a h m a n M.R. (2015). Effects of cage and barn rearing system on early laying performance of pullet. Bang. J. Anim. Sci., 44 :151-156.

S i m s e k U.G., C if t c i M., O z c el i k M., A z m an M.A., To n b a k F., O z h a n N. (2015). Effects of cinnamon and rosemary oils on egg production, egg quality, hatchability traits and blood serum mineral contents in laying quails (Coturnix coturnix japonica). Ankara Üniv. Vet. Fak. Derg., 62: $229-236$.

S i m s e k U.G., B a y k a 1 ir Y., E r i s i r M., B e n ze r F. (2018). Effects of conventional and organic rearing systems and hen age on oxidative stress parameters of blood and ovarian tissues in laying hens. Ankara Üniv. Vet. Fak. Derg., 65: 85-91.

S ingh R., Cheng K.M., Silversides F.G. (2009). Production performance and egg quality of four strains of laying hens kept in conventional cages and floor pens. Poultry Sci., 88: 256-264.

S t a n l e y V.G., N e 1 s o n D., D a 1 e y M.B. (2014). Evaluation of two laying systems (floor vs. cage) on egg production, quality and safety. Iran. J. Appl. Anim. Sci., 4: 597-601.

Tactacan G.B., Guenter W., Lewis N.J., Rodriguez-Lecompte J.C., House J.D. (2009). Performance and welfare of laying hens in conventional and enriched cages. Poult. Sci., 88: 698-707.

Tamzil M.H., Noor R.R., Hardjos woro P.S., Manalu W., Sumantri C. (2013). Acute heat stress responses of three lines of chickens with different heat shock protein (HSP)-70 genotypes. Int. J. Poultry Sci., 12: 264-272.

T ho m a s D.V., R a vind ra n V. (2005). Comparison of layer performance in cage and barn systems. J. Anim. Vet. Adv., 4: 554-556.

Tow bin H., Sta ehelin T., Gordon J. (1979). Electrophoretic transfer of proteins from polyacrylamide gels to nitrocellulose sheets: procedure and some applications. Proc. Natl. Acad. Sci., 76: 4350-4354.

Van Den Brand H., Parmentier H.K., Ke m p B. (2004). Effects of housing system (outdoor vs cages) and age of laying hens on egg characteristics. Br. Poultry Sci., 45: 745-752.

Yen i c e G., K a y nar O., I l er iturk M., H 1 r a F., Hay 1 r 11 A. (2016). Quality of eggs in different production systems. Czech J. Food Sci., 34: 370-376.

Y i $1 \mathrm{~m}$ a z-D i k m e n B., I p e k A., S a h a n U., P e t e k M., S o z c u A. (2016). Egg production and welfare of laying hens kept in different housing systems (conventional, enriched cage, and free range). PoultrySci., 95: 1564-1572.

Y i $1 \mathrm{~m}$ a z-D i k m e n B., I p e k A., S a h a n U., S o z c u A., B a y c a n S.C. (2017). Impact of different housing systems and age of layers on egg quality characteristics. Turk. J. Vet. Anim. Sci., 41: 77-84.

Zaghini A., Martelli G., Ronc ad a P., S i mi oli M., Rizzi L. (2005). Mannanoligosaccharides and aflatoxin B1 in feed for laying hens: Effects on egg quality, aflatoxins B1 and M1 residues in eggs and aflatoxin B1 levels in liver. Poultry Sci., 84: 825-832.

Zita L., Ledvinka Z., Tumova E., Kles a lova L. (2012). Technological quality of eggs in relation to the age of laying hens and Japanese quails. R. Bras. Zootec., 41: 2079-2084.

Received: 22 I 2018

Accepted: 25 V 2018 